\title{
A simple, rapid methodology for developing invasive species watch lists
}

\author{
Katelyn T. Faulkner ${ }^{\mathrm{a}, \mathrm{b}, *}$, Mark P. Robertson ${ }^{\mathrm{b}}$, Mathieu Rouget ${ }^{\mathrm{c}}$, John R.U. Wilson ${ }^{\mathrm{a}, \mathrm{d}}$ \\ ${ }^{a}$ Invasive Species Programme, South African National Biodiversity Institute, Private Bag X7, Claremont 7735, South Africa \\ ${ }^{\mathrm{b}}$ Centre for Invasion Biology, Department of Zoology and Entomology, University of Pretoria, Hatfield 0028, South Africa \\ ${ }^{c}$ Centre for Invasion Biology, School of Agricultural, Earth and Environmental Sciences, University of KwaZulu-Natal, Private Bag X01, Scottsville 3209, South Africa \\ ${ }^{\mathrm{d}}$ Centre for Invasion Biology, Department of Botany and Zoology, Stellenbosch University, Private Bag X1, Matieland 7602, South Africa
}

\section{A R T I C L E I N F O}

\section{Article history:}

Received 5 May 2014

Received in revised form 12 August 2014

Accepted 20 August 2014

\section{Keywords:}

Biological invasions

Biosecurity

Invasive elsewhere

Pre-border control

Propagule pressure

Risk assessment

\begin{abstract}
A B S T R A C T
Biosecurity schemes aim to prevent the introduction of species with a high invasion potential, without unduly restricting personal freedom and commercial activities. But invasive species risk assessments are time consuming, data intensive and expensive. Consequently, resource poor nations cannot implement these schemes. Here we develop a method for creating watch lists using the consistent predictors of invasion success-history of invasion, environmental suitability, and propagule pressure (measured respectively using the Global Invasive Species Database (GISD), environmental modelling, and tourism and trade data). We tested the approach for South Africa, at a national level for various taxa and at a provincial level for plants. Of 884 alien species listed in the GISD, 400 were potential invaders, with most occurring in high risk regions. When alien species in South Africa were evaluated there were many false-negatives (sensitivity of $32 \%$ for terrestrial and $40 \%$ for marine species), because the GISD is not comprehensive, but few false positives (specificity of $91 \%$ for terrestrial and $89 \%$ for marine species). The methodology was easy to apply at different political levels, but we found substantial overlaps between the national and provincial watch lists of plants. This simple technique is rapid, easily repeatable, flexible, transparent, works across taxa, and does not require substantial financial or scientific input. It can be used in any region of the world and at various political levels as an initial assessment of key threats. As such it may be an important step in developing biosecurity schemes for resource poor regions.
\end{abstract}

(c) 2014 Elsevier Ltd. All rights reserved.

\section{Introduction}

Intentionally and unintentionally introduced alien organisms can become invasive and cause economic and ecological impacts (Pimentel et al., 2001; Simberloff et al., 2013). To prevent or lessen the negative impacts, management strategies are needed that can target species that pose substantial threats. However, many countries have severely limited resources to implement the required biosecurity policies (McGeoch et al., 2010).

Often the most cost-effective way to manage alien species is to prevent their introduction (Leung et al., 2002; Simberloff, 2006; Simberloff et al., 2013; Wittenberg and Cock, 2005), but under international agreements (e.g. the World Trade Organisation's Agreement on the Application of Sanitary and Phytosanitary Measures), any restrictions that prevent introductions should not unduly restrict trade (Mumford, 2002; Simberloff, 2006).

\footnotetext{
* Corresponding author at: Centre for Invasion Biology, Department of Zoology and Entomology, University of Pretoria, Hatfield 0028, South Africa. Tel.: +27 (0) 12 4204396.

E-mail address: katelynfaulkner@gmail.com (K.T. Faulkner).
}

Moreover, as only a few alien species have become invasive (Williamson and Fitter, 1996) (e.g. <1\% of all tree and shrub species (Richardson and Rejmánek, 2011)), it is not feasible, desirable or necessary to prevent the introduction of all alien species (Mumford, 2002). Therefore, prevention strategies must focus on those with a demonstrably high potential impact.

To achieve this, pre-border invasive species risk assessments have been developed to evaluate introductions (Daehler et al., 2004; Kumschick and Richardson, 2013; Pheloung et al., 1999). Risk assessments, however, can be time-consuming, labour intensive and expensive. They are usually not suited for screening numerous species (McClay et al., 2010), are data intensive (Hayes and Barry, 2008), and for some taxa there are no methodologies in place (Kumschick and Richardson, 2013). As an example of the time and costs involved, the US National Research Council estimates that assessments for most planned introductions could take several years (Simberloff, 2005), while in Australia the annual cost of conducting such assessments might be as much as 300000 Australian dollars (Keller et al., 2007). While there may still be a net economic benefit to their implementation (Keller et al., 2007), such slow evaluations delay trade (Simberloff, 2006). 
Another widely used pro-active approach is to create watch lists that can be used to identify threats that require monitoring. These lists identify species with an invasion history that are absent from the study region but that could pose an invasion risk if introduced intentionally or unintentionally (e.g. 'black list-warning list' of Essl et al. (2011) and 'warn list' of Nehring and Klingenstein (2008)). Watch list methodologies are often less exhaustive than full preborder risk assessments, for example the 'Alert list' of the Belgian Harmonia system is based on only three criteria (the taxon is absent from Belgium, present in neighbouring regions that are eco-climatically similar, and has the potential for a high environmental impact (Branquart, 2007)). Watch lists are important tools that can aid in decision making and the development of preventative strategies and contingency plans (Nehring and Klingenstein, 2008; Parrott et al., 2009), for example, they can be used to direct monitoring and inspection efforts to limit accidental introductions (Bacon et al., 2012). Additionally, watch lists can serve as a list with which to prioritise post-border assessments and control efforts (Nehring and Klingenstein, 2008; Parrott et al., 2009).

Unfortunately, the methods and criteria used in developing watch lists are often not transparent and decisions are based solely on expert opinion. Here we aim to develop a transparent, simple, rapid, and inexpensive watch list methodology suitable for resource poor regions that is based on sound scientific principles and that could be used for the initial assessment of a wide range of taxa. We test the methodology using South Africa as a case study. The resultant methodology can be used in any region of the world and at various political levels for the rapid initial assessment of potential future invasive species.

\section{Methodology}

\subsection{Concept and criteria}

Our approach relies on three well-tested criteria: history of invasion, environmental suitability and propagule pressure (Fig. 1). To achieve our aim the evaluation criteria had to be applicable to many taxa and only readily available data could be utilised. Consequently, a history of invasion and environmental match were selected, as these criteria are consistent predictors of invasion success across taxa (Hayes and Barry, 2008; Hulme, 2012; Kolar and Lodge, 2001), and the data required (invasive species lists, occurrence records and environmental data) are readily available. Propagule pressure was additionally selected as this criterion is often a key determinant of establishment success (Hayes and Barry, 2008; Kolar and Lodge, 2001; Lockwood et al., 2005). The use of these three criteria for the identification of potentially invasive species is well established (e.g. Locke, 2009; Thuiller et al., 2005) and the resultant watch list includes any alien species that has not yet been introduced but that meets all three of these criteria (Fig. 1). Finally, as propagule pressure data are not available for most species, we used a readily available proxy (trade and tourism data) for propagule pressure and developed three thresholds for this criterion.

\subsection{Watch list methodology}

The proposed procedure for developing a watch list is set out in Fig. 2: (1) obtain a global list of invasive species; (2) filter out species already present in the target region (native species or alien species already introduced); (3) gather distribution data from the remaining species' native and invasive ranges; (4) use the distribution data to determine whether the target region is environmentally suitable or not; and (5) determine if there is propagule pressure from any region where the species occurs to the target region. We demonstrate this approach for South Africa.

\subsubsection{Obtain a global list of invasive species}

To identify species with a history of invasion, the Global Invasive Species Database (GISD) was accessed online (http://www.issg.org/database/welcome/) and taxonomic information for all listed species was extracted. Information on organism type and environment were additionally obtained from the database and were used to classify each species as either 'marine' (exclusively inhabits estuarine or marine environments) or 'terrestrial' (includes freshwater species).

\subsubsection{Filter out species present in the target region}

Species in the GISD that are already present in South Africa were identified using databases and references (Plants of Southern Africa: an online checklist version 3.0 (Morris and Glen, 1978); Wells et al., 1986; South African Plant Invaders Atlas 2012 (Henderson, 1998); CABI, 2013; Faulkner, unpublished data) as well as a literature search in Google Scholar (using the name of each species and "South Africa"). Species recorded as present in South Africa were removed from the GISD list, resulting in a list of candidate species ('candidate list').

\subsubsection{Gather distribution data from the native and introduced ranges}

For each candidate species, occurrence data from the native and introduced ranges were obtained from the Global Biodiversity Information Facility (GBIF, http://www.gbif.org/). Records with missing or incomplete coordinate data were excluded, and marine and terrestrial data were classified as appropriate. Species without any GBIF records were classified as 'requiring further study'.

2.2.4. Determine whether the target region is environmentally suitable

The level of complexity required of environmental matching techniques was evaluated using two simple climate matching techniques for terrestrial species and a third, more complex, published technique (Richardson and Thuiller, 2007). Additionally, for marine species a classification of the world's oceans was utilised.

Firstly, the Köppen-Geiger climate classification (Kottek et al., 2006) was employed to identify terrestrial locations that have similar climate zones to those present in mainland South Africa. As the Köppen-Geiger classification is relatively coarse, we secondly used a more stringent method based on the bioclimatic envelopes of the biomes found in South Africa (based on the classification of Olson et al. (2001)). South African biome data (truncated at the South African borders, but including Lesotho) were rasterized at a $10 \mathrm{~min} \times 10 \mathrm{~min}$ grid resolution and converted into point data. The terrestrial areas of the world with climatic conditions similar to each biome present in South Africa were then identified using the climate envelope modelling method BIOCLIM (method equivalent to 'marginal bioclimate' (Carpenter et al., 1993)). We considered four climatic parameters (mean annual temperature, minimum temperature of the coldest month, maximum temperature of the hottest month and mean annual precipitation) from the WorldClim $10 \mathrm{~min} \times 10 \mathrm{~min}$ data (Hijmans et al., 2005). These general climatic variables were selected so that the watch list methodology can be used for a wide range of taxa. To allow for more inclusive models (fewer omission errors), all predicted areas (percentiles 0-100) were included in the final prediction (see Fig. A1 in Appendix A). This analysis was performed in the opensource GIS software DIVA-GIS (version 7.5.0, http://www.divagis.org) to ensure that the methodology can be widely used.

The third method used for terrestrial taxa was based on a more complex method developed by Richardson and Thuiller (2007). Generalised additive models were used to identify regions of the world that are climatically analogous to the South African biomes 


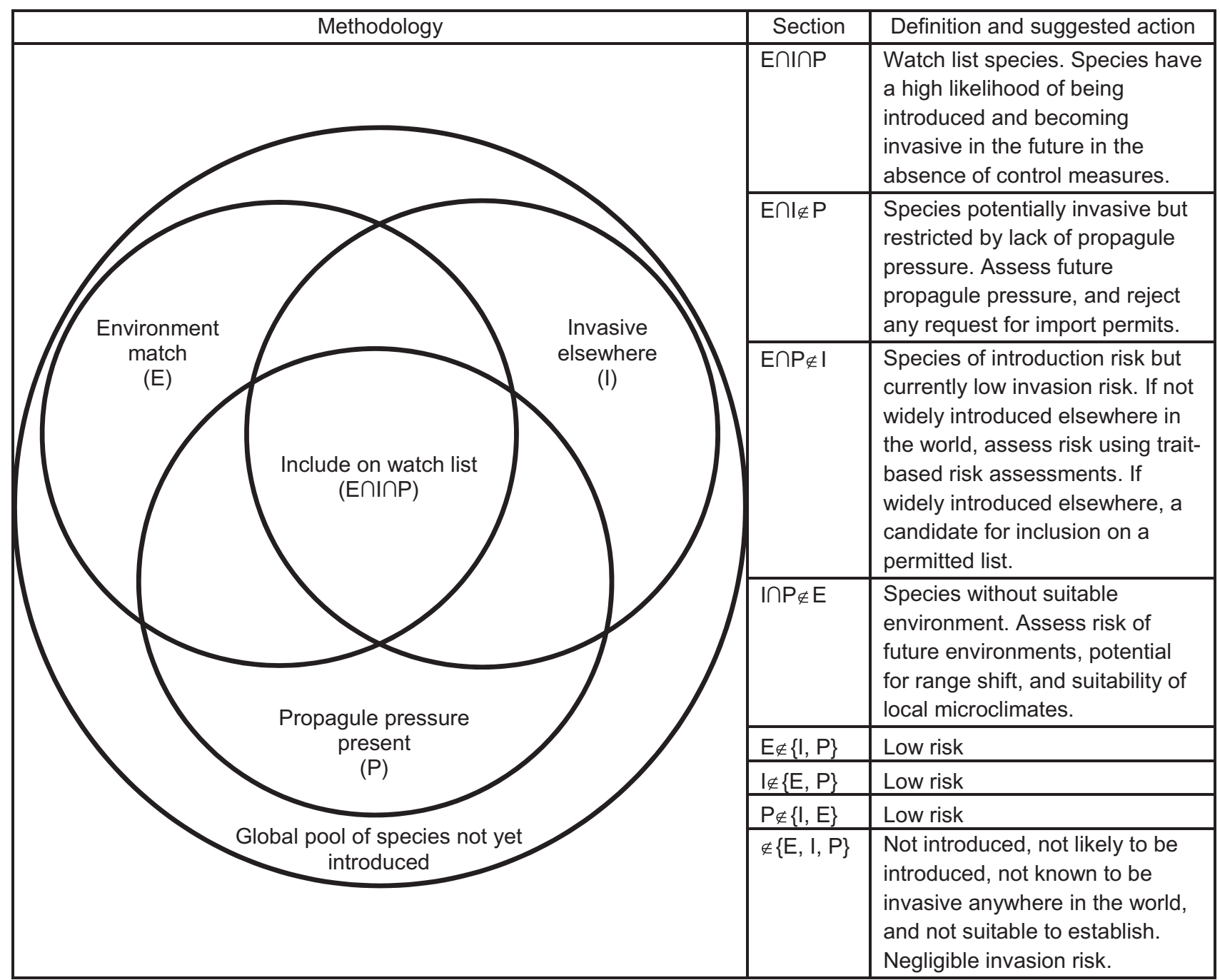

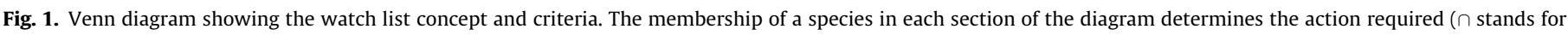
'intersection' and $\notin$ stands for 'excluding').

\begin{tabular}{|c|c|c|c|}
\hline Step & Methodology & Materials or techniques & Number of species \\
\hline 1 & 1: Histor & $\begin{array}{l}\text { Global Invasive Species Database } \\
\text { (http://www.issg.org/database) }\end{array}$ & 884 \\
\hline 2 & on? $\quad$ Not considered for & $\begin{array}{l}\text { South African species lists (native and } \\
\text { alien species) }\end{array}$ & $\begin{array}{l}403 \text { in South Africa } \\
481 \text { not in South Africa }\end{array}$ \\
\hline 3 & 3: Occurrence data avail & $\begin{array}{l}\text { Global Biodiversity Information Facility } \\
\text { (http://www.gbif.org/) }\end{array}$ & $\begin{array}{l}62 \text { no occurrence data } \\
419 \text { occurrence data } \\
\text { available }\end{array}$ \\
\hline 4 & Insufficient data & $\begin{array}{l}\text { For terrestrial species, Köppen-Geiger } \\
\text { climate classification (Kottek et al., 2006) } \\
\text { or climate envelope modelling } \\
\text { For marine species, Bailey ecoregion } \\
\text { classification (Bailey, 1998) }\end{array}$ & $\begin{array}{l}19 \text { do not occur in suitable } \\
\text { environments } \\
400 \text { occur in suitable } \\
\text { environments }\end{array}$ \\
\hline 5 & $\begin{array}{l}\text { Currently } \\
\text { study } \\
\text { low risk }\end{array}$ & $\begin{array}{l}\text { Trade and tourism data } \\
\text { Three potential thresholds, species from: } \\
\text { (1) high risk regions } \\
\text { (2) high and/or medium risk regions } \\
\text { (3) all regions with propagule pressure } \\
\text { present }\end{array}$ & $\begin{array}{l}0 \text { no propagule pressure } \\
\text { present } \\
400 \text { propagule pressure } \\
\text { present }\end{array}$ \\
\hline
\end{tabular}

Fig. 2. The watch list methodology and the number of species classified at each step for South Africa. 
(based on the vegetation classification used by Mucina and Rutherford (2006)). The usefulness of the approach used by Richardson and Thuiller (2007) was confirmed by results that showed that invasive plants in South Africa occur in regions that are climatically similar to the South African biomes. To validate the results of the two simple climate matching techniques, watch list results were compared to the results obtained when the method of Richardson and Thuiller (2007) was used.

For marine species, regions of the oceans with similar environments to those surrounding South Africa were identified (Fig. A1) using the oceans' ecoregion 'divisions' (Bailey, 1998). This classification is based on ocean hydrology (seasonal variation in temperature and salinity of water) and the physical properties that control ocean hydrology. As the divisions did not extend into the continental shelf zones and as the continental shelf can be interpreted as a variation of the related ecoregion (Bailey, 1998, p. 19), each ecoregion was extended accordingly. This classification was selected as salinity and temperature are good predictors of invasion success in marine species and as these variables have been recommended for use in risk assessments (Barry et al., 2008). Additionally, this method is likely to be more rapid than those used in other assessments developed for marine organisms (e.g. Euclidean distance (Keller et al., 2011)).

In each case occurrence data for the candidate species were superimposed onto maps of the environmental match results (maptools package (Bivand and Lewin-Koh, 2013); R version 2.13.1). Species on the candidate list that do not occur in regions that are environmentally similar to South Africa were classified as a low current invasion risk.

\subsubsection{Determine if there is propagule pressure from any region where} the species occurs

Next we determined which of the candidate species located in climatically suitable regions are present in regions with propagule pressure to South Africa. Import and tourism data for the period 2006-2011 were obtained from the South African Revenue Service (http://www.sars.gov.za) and Statistics South Africa (http:// www.statssa.gov.za), and the percentage contribution of each country to South Africa's mean imports and tourism (2006-2011) was determined. From the initial analysis it was apparent that countries could be classified, based on natural breaks in the data, into three broad groups: those that contribute $>5 \%$ to South Africa's total mean imports or tourism (i.e. high risk of propagules being introduced); those that contribute 1-5\% (medium risk); and those that contribute $<1 \%$ (low risk). To evaluate the impact different thresholds for this criterion would have on the watch list, we then determined which candidate species would be retained on the watch list if (1) only species from high risk regions were included, (2) species from high and/or medium risk regions were included and (3) species from any region with propagule pressure present (i.e. high, medium and low) were included (Fig. A2). If a species occurs in regions with varying risk (e.g. high and low risk regions) the highest level of risk was used.

The watch list was therefore determined by superimposing occurrence data for candidate species onto maps of combined environmental match and propagule pressure results (Fig. 3). For these analyses maps of the world's political borders (http:// wwwn.cdc.gov/epiinfo/, 2013) and exclusive economic zones (Version 7, www.marineregions.org/, 2012) were used.

\subsection{Methodology evaluation}

To evaluate the methodology we re-ran the analysis using alien species listed in the GISD but which are already present in South Africa (i.e. species, excluding natives, that were filtered out in step 2 on Fig. 2) as well as alien species that are already present in South
Africa but which are not included in the GISD (Faulkner, unpublished data). We then determined the percentage of invasive species accurately predicted to be invasive (i.e. model sensitivity). We considered species to be invasive if classified as such in an alien species list or if regulated under South African invasive species legislation (Conservation of Agricultural Resources Act and National Environmental Management Biodiversity Act). Similarly, we calculated the percentage of non-invasive alien species accurately predicted as non-invasive (i.e. model specificity), where noninvasive species were those that are listed as alien but not invasive, and that are not listed in the regulations.

To determine the degree to which data gaps in the GISD (i.e. species that are invasive but are not listed in the GISD) influenced watch list sensitivity, the sensitivity of the watch list was additionally determined using only South African GISD species which could be confirmed as alien in South Africa using independent records.

To test the applicability of the methodology at a different geographic scale, watch lists of plants were developed for two climatically dissimilar South African provinces: the Western Cape and Limpopo. Coastal regions of the Western Cape have a Mediterranean-type climate and most rainfall is received in winter (for example, Cape Town in the Western Cape receives 251-300 mm of rainfall in winter and $50-100 \mathrm{~mm}$ in summer (Kruger, 2007)), while inland regions are more arid. In contrast, the Limpopo province experiences dry, warm winters and hot summers, during which most rainfall is received (for example, Polokwane in Limpopo receives $\leq 50 \mathrm{~mm}$ of rainfall in winter and $151-200 \mathrm{~mm}$ in summer (Kruger, 2007)). As the environmental matching techniques for terrestrial species resulted in similar national watch lists (see results), for this analysis only one environmental matching technique, the Köppen-Geiger climate classification, was used. Additionally, it was assumed that propagule pressure for these provinces was the same as for South Africa as a whole. The provincial watch lists were compared to each other and to the plants on the national watch list developed using the Köppen-Geiger climate classification. Thus environmental suitability is the only factor to influence differences between these watch lists.

\section{Results}

The results at each step in the protocol are summarised in Fig. 2. Of 884 species with a history of invasion listed in the GISD (step 1), 403 are already present in South Africa (step 2). Of the resulting 481 candidate species, occurrence data were available for 419 (87\%) (step 3). The 62 species that did not have occurrence data available will require further study (Table A1). The four environmental matching techniques (three terrestrial and one marine technique) identified 400 species that occur in regions that are environmentally similar to South Africa. Only 19 species occur in environmentally unsuitable regions and thus currently pose a low invasion risk (step 4). The environmental matching technique utilised had little influence on the number and taxonomic identity of the terrestrial species that occur in regions that are environmentally similar to South Africa (Tables 1 and A2). All species from regions with a close environmental match to South Africa were also found in regions that have propagule pressure present (step 5). Although larger portions of the globe were identified as low or medium risk than high risk regions (Fig. 3), few species were found in medium or low risk regions that did not also occur in high risk regions (Tables 2 and A2). Thus, the propagule pressure thresholds had little influence on the number of species to be included on the watch list (Table 2).

The evaluation of the watch list using a list of alien species present in South Africa showed that watch list sensitivity was low (32\% 
(a)
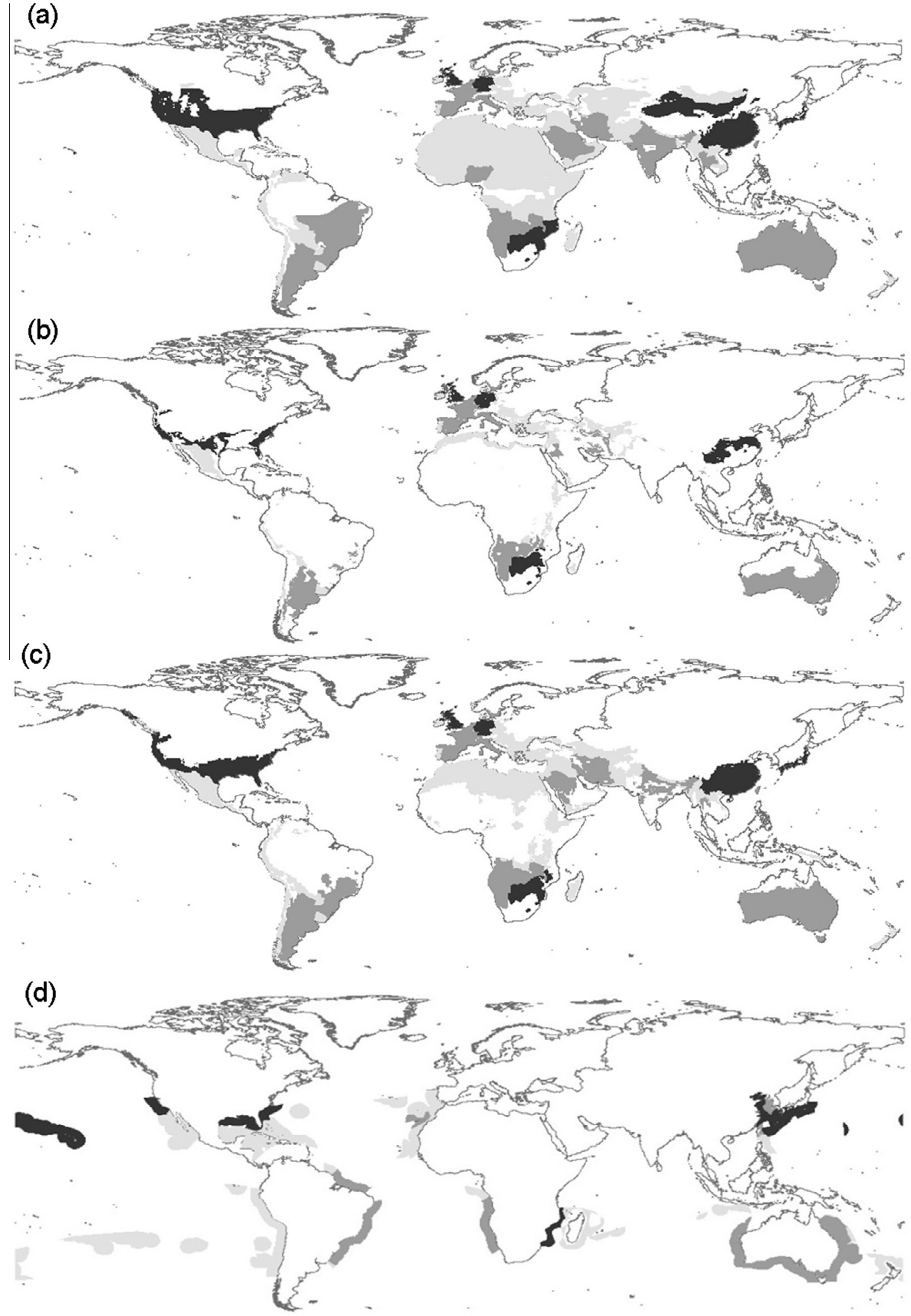

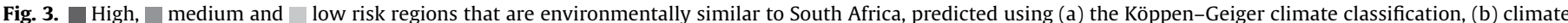

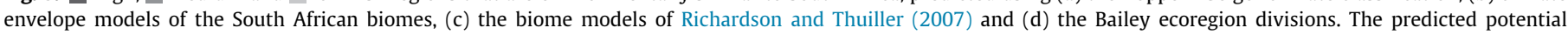

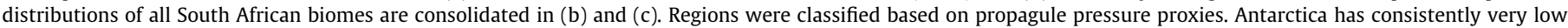
environmental similarity to South Africa (not shown).

and $40 \%$ for terrestrial and marine species, respectively) but specificity was high (91\% and $89 \%$ for terrestrial and marine species, respectively; Table 3). Furthermore, watch list sensitivity and specificity were consistent across the three terrestrial environmental matching techniques (Table 3 ). When evaluated using only the
GISD listed species that are present in South Africa, watch list sensitivity was high (95\% and $88 \%$ for terrestrial and marine species, respectively; Table 3 ). These results demonstrate that the methodology's low sensitivity could be due to the large number of invasive species that are not recorded in the GISD. 
Table 1

Number of species that occur in environmentally suitable regions, identified using four environmental matching techniques.

\begin{tabular}{ll}
\hline Environmental match & Number of species \\
\hline Köppen-Geiger & 363 \\
Climate envelope & 320 \\
Richardson and Thuiller (2007) & 356 \\
Bailey ecoregions & 35 \\
All techniques & 400 \\
\hline
\end{tabular}

\section{Table 2}

Number of watch list species identified using the environmental matching techniques and propagule pressure thresholds. Propagule pressure thresholds are based on species occurrence in high risk regions, high and/or medium risk regions or any region with propagule pressure present.

\begin{tabular}{lrll}
\hline \multirow{2}{*}{ Environmental match } & \multicolumn{3}{l}{ Propagule pressure thresholds } \\
\cline { 2 - 4 } & High & $\begin{array}{l}\text { High and/or } \\
\text { medium }\end{array}$ & $\begin{array}{l}\text { All regions with } \\
\text { propagule pressure }\end{array}$ \\
\hline Köppen-Geiger & 319 & 347 & 363 \\
Climate envelope & 299 & 314 & 320 \\
Richardson and & 318 & 344 & 356 \\
$\quad$ Thuiller (2007) & & & 35 \\
Bailey ecoregions & 32 & 33 & 400 \\
All techniques & 351 & 380 & \\
\end{tabular}

Few differences were found between national and provincial watch lists of plants developed using the Köppen-Geiger classification. Of the plant species on the national watch list (183 species), the majority (125 species) were included on both the Western Cape and Limpopo watch lists (Table A2). Of the 183 plant species on the national watch list, only 19 species were not included on the watch list for the Western Cape, while 48 species were not included on the watch list for Limpopo (Table A2).

\section{Discussion}

Preventing the introduction of invasive species is often much less costly than managing them after introduction (Leung et al., 2002; Simberloff, 2006; Simberloff et al., 2013; Wittenberg and Cock, 2005). Given the importance of trade and the lack of resources dedicated to biosecurity a rapid method is needed to identify species which should not be intentionally or unintentionally introduced and which should be the focus for monitoring programmes. Using a simple five step process we developed an initial watch list of 400 species for South Africa.

The methodology presented here has several advantages. As easily accessible data, open-source software and simple techniques were used, anyone with moderate GIS experience and internet access can implement the procedure. Assessments using this methodology are also extremely rapid. For example, once the required data were obtained and the criteria for assessment were in place over 800 species from a wide variety of taxa were assessed in one day. The rapidity and flexibility of this methodology also means that watch lists can be easily updated and extended, e.g. to not just include history of invasiveness, but also history of impact elsewhere (Blackburn et al., 2014; Kulhanek et al., 2011). Finally, the methodology can be used to develop watch lists for implementation at various political levels. The rapidity, simplicity, flexibility and low cost of this methodology make it particularly useful in resource poor regions where biosecurity is urgently needed (McGeoch et al., 2010).

In creating a rapid, simple, generic watch list method there was, of course, a trade-off with accuracy. Consequently, few species with a low invasion potential were included on the watch list (high specificity), but many invasive species were not listed (low sensitivity). We believe, however, that the low sensitivity was largely due to the quality of the data sources used rather than the methodology, and that data gaps in the GISD had a particularly large influence on the methodology's sensitivity. For example, due to geographical and taxonomic biases (McGeoch et al., 2012), the GISD only includes approximately 15-20\% of any country's known invasive species (Westphal et al., 2008). Thus, theoretically 80-85\% of the invasive species in South Africa are not listed, and consequently if assessed using a complete and independent list of invasive species, watch list sensitivity will never exceed 15-20\%. Despite this, as the GISD is the most comprehensive invasive species database (McGeoch et al., 2012) it was the best database to serve our purpose. To decrease omission errors the GISD data could be supplemented with data from other databases (e.g. CAB International's Invasive Species Compendium), however, such action may be time consuming. Although data gaps in the GISD are the main source of error, other potential sources of error include geographical and taxonomic biases in the GBIF distribution data (Yesson et al., 2007), taxonomic uncertainties, and the possible inclusion of unsuitable records during environmental matching (van Wilgen et al., 2009). Furthermore, due to the simplicity and coarse scale of the propagule pressure proxy data the likelihood of introduction may be overestimated. The use of finer scale data may have improved the analysis and decreased the number of the species on the watch list, however, it is unlikely that these data will be available for resource poor regions. Additionally, although such coarse propagule pressure proxies do not always correlate with the number of species introduced (e.g. Areal et al., 2008), trade and tourism data have been used to successfully predict introductions (Tatem et al., 2006; Thuiller et al., 2005).

The watch list methodology identified hundreds of species as potential future invaders for South Africa. This result was not surprising as the wide range of environments experienced in South Africa (as demonstrated by the environmental matching results) makes the country suitable for organisms from many parts of the globe (Richardson and Thuiller, 2007). Moreover, South Africa is already severely affected by a large number of invasive species from a wide variety of taxa (MacDonald et al., 1986; Picker and Griffiths, 2011; Richardson et al., 2000). The number and taxonomic identity of the identified terrestrial species varied little across the three environmental matching techniques. Thus it may be concluded that either the Köppen-Geiger classification or the

Table 3

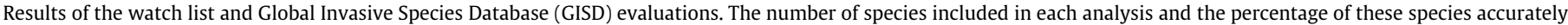
predicted to be invasive (sensitivity) or non-invasive (specificity) are given.

\begin{tabular}{|c|c|c|c|c|c|c|}
\hline \multirow[t]{3}{*}{ Environmental match } & \multicolumn{4}{|c|}{ Watch list evaluation } & \multirow{2}{*}{\multicolumn{2}{|c|}{$\begin{array}{l}\text { GISD evaluation } \\
\text { Sensitivity } \\
\end{array}$}} \\
\hline & \multicolumn{2}{|l|}{ Sensitivity } & \multicolumn{2}{|l|}{ Specificity } & & \\
\hline & Number of species & $(\%)$ & Number of species & $(\%)$ & Number of species & $(\%)$ \\
\hline Köppen-Geiger & 394 & 31.73 & 258 & 91.09 & 132 & 95.45 \\
\hline Climate envelope & 394 & 31.73 & 258 & 91.09 & 132 & 95.45 \\
\hline Richardson and Thuiller (2007) & 394 & 31.73 & 258 & 91.09 & 132 & 94.70 \\
\hline Bailey ecoregions & 10 & 40.00 & 9 & 88.89 & 8 & 87.50 \\
\hline
\end{tabular}


climate envelope technique can be utilised for watch list development, and that these simple methods are as effective as the more complex technique proposed by Richardson and Thuiller (2007). Finally, despite only testing and utilising one environmental matching technique for marine species, we believe that assessing the level of complexity required for such work would be a beneficial avenue of future research. Surprisingly, the vast majority of species occurring in environmentally similar regions additionally occur in high risk regions, and as a consequence the three propagule pressure thresholds had little influence on the watch list. It is possible that economically developed, high risk regions that play a large role in international trade have a relatively large number of invasive species (McGeoch et al., 2010; Westphal et al., 2008). However, this inconsistency may also be due to the geographically biased nature of invasion ecology (McGeoch et al., 2010; Pyšek et al., 2008) or again to biases in the GISD and GBIF (McGeoch et al., 2012; Yesson et al., 2007).

Despite the wide range of climates experienced in South Africa, overlapping national and provincial watch lists of plants demonstrated that for South Africa a national plant watch list is sufficient. For other taxa introduced to South Africa, or for other countries that span multiple biogeographical regions (e.g. Brazil) lists at lower political levels may be preferable. Lists at lower political levels would also enable trade restrictions for native species to be put in place (Simberloff, 2006). However, legally enacting such lists may be difficult and, as provincial border-control would be required, list enforcement would be labour intensive and expensive.

Watch list methodologies are useful tools, however, species that are not on the watch list should not be viewed as posing no risk and any species that is not listed due to a lack of assessment must be evaluated (Dehnen-Schmutz, 2011; Simberloff, 2006). For instance, species with no invasion history (Mack, 1996) are not taken into account by the watch list methodology presented here and must still be evaluated using trait based pre-border risk assessments. Finally, species identified as a current low invasion risk should still be viewed with caution and reassessed when new information becomes available, databases are updated or in instances of environmental and propagule pressure change. Such a pro-active approach is additionally recommended as it would facilitate the prompt assessment of species newly identified as invasive elsewhere.

\section{Conclusion}

Watch lists are valuable biosecurity tools, but to be useful in resource poor regions the methodologies used for their development must be rapid, inexpensive and flexible. The technique demonstrated here meets the needs of resource poor regions but is also transparent and based on sound scientific principles. To create a rapid and flexible watch list method only simple criteria and techniques could be utilised, and although we show here that these simple techniques can be as effective as more complex ones, there was a trade off with accuracy. Consequently, many potential invasive species were not included on the watch list. We believe that this low sensitivity is not due to the methodology but rather to the quality of the data sources utilised, and that this should serve to highlight the importance of maintaining and updating invasive species databases. Finally, we hope that this methodology will stimulate further discussion and research on developing biosecurity methods for resource poor regions.

\section{Role of the funding source}

The funder had no role in study design; the collection, analysis and interpretation of data; writing the manuscript and the decision to submit the manuscript for publication.

\section{Acknowledgements}

This work was supported by the South African National Department of Environment Affairs through its funding of the South African National Biodiversity Institute Invasive Species Programme. Additional funding was provided by the DST-NRF Centre for Invasion Biology. M.R. acknowledges funding from the South African Research Chairs Initiative of the Department of Science and Technology and National Research Foundation of South Africa. We thank Dave Richardson and Wilfried Thuiller for kindly providing data and William Froneman for advice on marine environmental matching techniques. Thank you to Fatima Parker-Allie and Andrea Hahn for helping us obtain GBIF data.

\section{Appendix A. Supplementary material}

Supplementary data associated with this article can be found, in the online version, at http://dx.doi.org/10.1016/j.biocon.2014.0 8.014 .

\section{References}

Areal, F.J., Touza, J., MacLeod, A., Dehnen-Schmutz, K., Perrings, C., Palmieri, M.G., Spence, N.J., 2008. Integrating drivers influencing the detection of plant pests carried in the international cut flower trade. J. Environ. Manage. 89, 300-307.

Bacon, S.J., Bacher, S., Aebi, A., 2012. Gaps in border controls are related to quarantine alien insect invasions in Europe. PLoS One 7, e47689.

Bailey, R.G., 1998. Ecoregions: The Ecosystem Geography of the Oceans and the Continents. Springer-Verlag, New York.

Barry, S.C., Hayes, K.R., Hewitt, C.L., Behrens, H.L., Dragsund, E., Bakke, S.M., 2008. Ballast water risk assessment: principles, processes, and methods. ICES J. Mar. Sci. $65,121-131$.

Bivand, R., Lewin-Koh, N., 2013. maptools: Tools for reading and handling spatial objects [WWW Document]. URL <http://cran.r-project.org/package=maptools> (accessed 11.11.13).

Blackburn, T.M., Essl, F. Evans, T., Hulme, P.E. Jeschke, J.M., Kühn, I., Kumschick, S. Marková, Z., Mrugała, A., Nentwig, W., Pergl, J., Pyšek, P., Rabitsch, W., Ricciardi, A., Richardson, D.M., Sendek, A., Vilà, M., Wilson, J.R.U., Winter, M., Genovesi, P., Bacher, S., 2014. A unified classification of alien species based on the magnitude of their environmental impacts. PLoS Biol. 12, e1001850.

Branquart, E., 2007. Guidelines for environmental impact assessment and list classification of non-native organisms in Belgium. Belgium Forum on Invasive Species.

CABI, 2013. Invasive Species Compendium [WWW Document]. CAB Int. URL <www.cabi.org/isc> (accessed 11.11.13).

Carpenter, G., Gillison, A.N., Winter, J., 1993. DOMAIN: a flexible modelling procedure for mapping potential distributions of plants and animals. Biodivers. Conserv. 2, 667-680.

Daehler, C.C., Denslow, J.S., Ansari, S., Kuo, H.-C., 2004. A risk-assessment system for screening out invasive pest plants from Hawaii and other Pacific Islands. Conserv. Biol. 18, 360-368.

Dehnen-Schmutz, K., 2011. Determining non-invasiveness in ornamental plants to build green lists. J. Appl. Ecol. 48, 1374-1380.

Essl, F., Nehring, S., Klingenstein, F., Milasowszky, N., Nowack, C., Rabitsch, W., 2011. Review of risk assessment systems of IAS in Europe and introducing the German-Austrian Black List Information System (GABLIS). J. Nat. Conserv. 19, 339-350.

Hayes, K.R., Barry, S.C., 2008. Are there any consistent predictors of invasion success? Biol. Invasions 10, 483-506.

Henderson, L., 1998. Southern African plant invaders atlas (SAPIA). Appl. Plant Sci. $12,31-32$.

Hijmans, R.J., Cameron, S.E., Parra, J.L., Jones, P.G., Jarvis, A., 2005. Very high resolution interpolated climate surfaces for global land areas. Int. J. Climatol. 25, 1965-1978.

Hulme, P.E., 2012. Weed risk assessment: a way forward or a waste of time? J. Appl. Ecol. 49, 10-19.

Keller, R.P., Lodge, D.M., Finnoff, D.C., 2007. Risk assessment for invasive species produces net bioeconomic benefits. Proc. Natl. Acad. Sci. USA 104, 203-207.

Keller, R.P., Drake, J.M., Drew, M.B., Lodge, D.M., 2011. Linking environmental conditions and ship movements to estimate invasive species transport across the global shipping network. Divers. Distrib. 17, 93-102.

Kolar, C.S., Lodge, D.M., 2001. Progress in invasion biology: predicting invaders. Trends Ecol. Evol. 16, 199-204.

Kottek, M., Grieser, J., Beck, C., Rudolf, B., Rubel, F., 2006. World map of the KöppenGeiger climate classification updated. Meteorol. Zeitschrift 15, 259-263.

Kruger, A.C., 2007. Climate of South Africa: Precipitation. South African Weather Service, Pretoria. 
Kulhanek, S.A., Ricciardi, A., Leung, B., 2011. Is invasion history a useful tool for predicting the impacts of the world's worst aquatic invasive species? Ecol. Appl. 21, 189-202.

Kumschick, S., Richardson, D.M., 2013. Species-based risk assessments for biological invasions: advances and challenges. Divers. Distrib. 19, 1095-1105.

Leung, B., Lodge, D.M., Finnoff, D., Shogren, J.F., Lewis, M.A., Lamberti, G., 2002. An ounce of prevention or a pound of cure: bioeconomic risk analysis of invasive species. Proc. R. Soc. London, Ser. B: Biol. Sci. 269, 2407-2413.

Locke, A., 2009. A screening procedure for potential tunicate invaders of Atlantic Canada. Aquat. Invasions 4, 71-79.

Lockwood, J.L., Cassey, P., Blackburn, T.M., 2005. The role of propagule pressure in explaining species invasions. Trends Ecol. Evol. 20, 223-228.

MacDonald, I.A.W., Kruger, F.J., Ferrar, A.A., 1986. The Ecology and Management of Biological Invasions in southern Africa. Oxford University Press, Cape Town.

Mack, R.N., 1996. Predicting the identity and fate of plant invaders: emergent and emerging approaches. Biol. Conserv. 78, 107-121.

McClay, A., Sissons, A., Wilson, C., Davis, S., 2010. Progress in development of a modified Australian weed risk assessment system to predict weediness of plant species introduced into Canada. In: Rindos, E. (Ed.), Proceedings of the 5th Biennial Weeds Across Borders Conference. Center for Invasive Plant Management, Shepherdstown, pp. 41-45.

McGeoch, M.A., Butchart, S.H.M., Spear, D., Marais, E., Kleynhans, E.J., Symes, A., Chanson, J., Hoffmann, M., 2010. Global indicators of biological invasion: species numbers, biodiversity impact and policy responses. Divers. Distrib. 16, 95-108.

McGeoch, M.A., Spear, D., Kleynhans, E.J., Marais, E., 2012. Uncertainty in invasive alien species listing. Ecol. Appl. 22, 959-971.

Morris, J.W., Glen, H.F., 1978. Précis, the national herbarium of South Africa (PRE) computerized information system. Taxon 27, 449-462.

Mucina, L., Rutherford, M.C., 2006. The vegetation of South Africa, Lesotho and Swaziland. South African National Biodiversity Institute, Pretoria.

Mumford, J.D., 2002. Economic issues related to quarantine in international trade. Eur. Rev. Agric. Econ. 29, 329-348.

Nehring, S., Klingenstein, F., 2008. Aquatic alien species in Germany - listing system and options for action. NEOBIOTA 7, 19-33.

Olson, D.M., Dinerstein, E., Wikramanayake, E.D., Burgess, N.D., Powell, G.V.N., Underwood, E.C., D’Amico, J.A., Itoua, I., Strand, H.E., Morrison, J.C., Loucks, C.J., Allnutt, T.F., Ricketts, T.H., Kura, Y., Lamoreux, J.F., Wettengel, W.W., Hedao, P. Kassem, K.R., 2001. Terrestrial ecoregions of the world: a new map of life on earth. Bioscience 51, 933-938.

Parrott, D., Roy, S., Baker, R., Cannon, R., Eyre, D., Hill, M., Wagner, M., Preston, C., Roy, H., Beckmann, B., Copp, G.H., Edmonds, N., Ellis, J., Laing, I., Britton, J.R., Gozlan, R.E., Mumford, J., 2009. Horizon Scanning for New Invasive Non-Native Animal Species in England. Natural England, Sheffield.

Pheloung, P.C., Williams, P.A., Halloy, S.R., 1999. A weed risk assessment model for use as a biosecurity tool evaluating plant introductions. J. Environ. Manage. 57, 239-251.

Picker, M., Griffiths, C.L., 2011. Alien and Invasive Animals: A South African Perspective. Struik Nature, Cape Town.
Pimentel, D., McNair, S., Janecka, J., Wightman, J., Simmonds, C., O'Connell, C., Wong E., Russel, L., Zern, J., Aquino, T., Tsomondo, T., 2001. Economic and environmental threats of alien plant, animal, and microbe invasions. Agric. Ecosyst. Environ. 84, 1-20.

Pyšek, P., Richardson, D.M., Pergl, J., Jarošík, V., Sixtová, Z., Weber, E., 2008. Geographical and taxonomic biases in invasion ecology. Trends Ecol. Evol. 23, $237-244$.

Richardson, D.M., Bond, W.J., Dean, W.R.J., Higgins, S.I., Midgley, G.F., Milton, S.J., Powie, L.W., Rutherford, M.C., Samways, M.J., Schulze, R.E., 2000. Invasive alien species and global change: a South African perspective. In: Mooney, H.A., Hobbs R.J. (Eds.), Invasive Species in a Changing World. Island Press, Washington, pp. 303-349.

Richardson, D.M., Thuiller, W., 2007. Home away from home-objective mapping of high-risk source areas for plant introductions. Divers. Distrib. 13, 299-312.

Richardson, D.M., Rejmánek, M., 2011. Trees and shrubs as invasive alien species - a global review. Divers. Distrib. 17, 788-809.

Simberloff, D., 2005. The politics of assessing risk for biological invasions: the USA as a case study. Trends Ecol. Evol. 20, 216-222.

Simberloff, D., 2006. Risk assessments, blacklists, and white lists for introduced species: are predictions good enough to be useful? Agric. Resour. Econ. Rev. 35, $1-10$.

Simberloff, D., Martin, J.-L., Genovesi, P., Maris, V., Wardle, D.A., Aronson, J., Courchamp, F., Galil, B., García-Berthou, E., Pascal, M., Pyšek, P., Sousa, R., Tabacchi, E., Vilà, M., 2013. Impacts of biological invasions: what's what and the way forward. Trends Ecol. Evol. 28, 58-66.

Tatem, A.J., Hay, S.I., Rogers, D.J., 2006. Global traffic and disease vector dispersal. Proc. Natl. Acad. Sci. USA 103, 6242-6247.

Thuiller, W., Richardson, D.M., Pyšek, P., Midgley, G.F., Hughes, G.O., Rouget, M., 2005. Niche-based modelling as a tool for predicting the risk of alien plant invasions at a global scale. Glob. Chang. Biol. 11, 2234-2250.

van Wilgen, N.J., Roura-Pascual, N., Richardson, D.M., 2009. A quantitative climatematch score for risk-assessment screening of reptile and amphibian introductions. Environ. Manage. 44, 590-607.

Wells, M.J., Balsinhas, A.A., Joffe, H., Engelbrecht, V.M., Harding, G., Stirton, C.H., 1986. A catalogue of problem plants in Southern Africa, 1986. Memoirs of the Botanical Survey of South Africa. No. 53.

Westphal, M.I., Browne, M., MacKinnon, K., Noble, I., 2008. The link between international trade and the global distribution of invasive alien species. Biol. Invasions 10, 391-398.

Williamson, M., Fitter, A., 1996. The varying success of invaders. Ecology 77, 16611666.

Wittenberg, R., Cock, M.J.W., 2005. Best practices for the prevention and management of invasive alien species. In: Mooney, H.A., Mack, R.N., McNeely, J.A., Neville, L.E., Schei, P.J., Wage, J.K. (Eds.), Invasive Alien Species: A New Synthesis. Island Press, Washington, pp. 209-232.

Yesson, C., Brewer, P.W., Sutton, T., Caithness, N., Pahwa, J.S., Burgess, M., Gray, W.A., White, R.J., Jones, A.C., Bisby, F.A., Culham, A., 2007. How global is the global biodiversity information facility? PLoS One 2, e1124. 